Results Optimal cut-off values for automatically detected inspiratory and expiratory wheezing were $2 \%$ and $3 \%$, respectively. The resulting sensitivity of inspiratory and expiratory wheezing were $83.3 \%$ and $84.6 \%$, and the specificity $78 \%$ and $82.5 \%$, respectively (Figure). The inter-rater agreement was moderate with a Fleiss' Kappa of 0.59 for inspiratory wheezing and 0.54 for expiratory wheezing.

Conclusion Computerised lung sound analysis is feasible already during the first months of life and provides quantitative and noninvasive information about the extent of wheezing, whereas the assessment by trained clinicians was subjective and only moderate in inter-rater agreement.

\section{PS-180 MEASUREMENT OF FRACTIONAL NITRIC OXIDE CONCENTRATION IN EXHALED BREATH IN MONITORING THE PAEDIATRIC PATIENT}

A Aramburu, M Ballesta, C Juzga, J Ferrés. Pediatrics, Hospital de la Santa Creu i Sant Pau, Barcelona, Spain

\subsection{6/archdischild-2014-307384.476}

Introduction Fraction of exhaled nitric oxide (FeNO) is a biomarker of eosinophilic airway inflammation, determining airway responsiveness to inhaled corticosteroid treatment and atopy. It is a non-invasive, reproducible, simple and safe method of measuring airway inflammation that provides a complementary tool to other ways of assessing airways disease, including asthma.

Methods Retrospective descriptive study. The data of 99 paediatric patients attending outpatients in paediatric pneumology (from July 2012 to June 2013) with 2 consecutive measurements of FeNO was included. Characteristics of sex, age, exerciseinduced asthma, prick test, FeNO, forced expiratory volume (FEV1), asthma control test (ACT) and baseline asthma treatment were analysed.

The variations in FeNO, ACT, exercise-induced asthma and FEV 1 after intensifying or initiating treatment were collected.

Results 99 patients, 46 men and 53 women were included. The mean age of the study population was 12.5 years $(5-17)$ with an initial average ACT of 20.13 (10-25), FEV1 of 78\% (42-132\%) and an initial FeNO of 51.02 (7 -170). 95.8\% had a positive prick test. 45 exercise tests were performed, in 18 (40\%) of them a decrease in FEV1 $>10 \%$ was found. 15.2\% of the patients were not taking any treatment at the first visit, $23.3 \%$ received Smart therapy (long-acting beta2- agonists and inhaled corticosteroids), 20.2\% beta2- adrenergic agonist, 15\% therapy Smart + montelukast, inhaled corticosteroids $13.1 \%$ and $13 \%$ other combined therapies.

A statistically significant decrease in FeNO to $31.9 \mathrm{t}=6.594$ ( $\mathrm{p}=0.000)$ was found after starting treatment, intensifying or modifying basic treatment. A statistically significant correlation was found between FeNO decrease and ACT improvement $r=-$ $0398(p=0.000)$ and FEV1 $r=-0.260(p=0.01)$ between the first and the second visit.

Conclusions The decrease in airway inflammation correlates with an increased subjective control of the disease and also with a higher forced expiratory volume. In our series of patients these results were achieved increasing Smart treatment therapy, as well as adding inhaled corticosteroid in patients not previously taking, including other treatment options. The value of FeNO also served to identify non-compliant patients.

\section{PS-180a ANTIBIOTICS USE IN INFANTS HOSPITALISED WITH ACUTE BRONCHIOLITIS IN SOUTHEAST NORWAY}

${ }^{1} \mathrm{E}$ Dahl-Hansen, ${ }^{1} \mathrm{HO}$ Skjerven, ${ }^{2} \mathrm{P}$ Mowinckel, ${ }^{1} \mathrm{KH}$ Carlsen, ${ }^{2} \mathrm{KCL}$ Carlsen. ${ }^{1}$ Institute of Clinical Medicine, University of Oslo, Oslo, Norway; ${ }^{2}$ Departement of Pediatrics, Oslo University Hospital, Oslo, Norway

10.1136/archdischild-2014-307384.477

Background Airway viruses, most often respiratory syncytial virus, cause acute bronchiolitis. Despite no evidence of its effect, $30-100 \%$ of hospitalised children globally receive antibiotics. The aim of the study was to identify the rate of antibiotics use in hospitalised infants with moderate to severe acute bronchiolitis in Norway.

Methods 404 infants hospitalised with moderate to severe acute bronchiolitis in eight centres in Southeast Norway completed a clinical trial of inhaled racemic adrenaline[1] was included in this study. The mean length of stay was 3.3 days, $43.6 \%$ received oxygen support, $29.0 \%$ nasogastric tube feeding and $7.4 \%$ ventilatory support.

Results $8.4 \%(\mathrm{n}=34)$ of the patients received systemic antibiotics, (17 intravenous and 17 oral), most commonly penicillin (41\%), ampicillin (26\%) and gentamicin (24\%). Use of antibiotics versus no antibiotics was significantly associated with a longer hospital stay (mean 135.5 h (95\% CI 117.0-154.1) vs $65.9 \mathrm{~h}$ (95\% CI 47.2-85.1), $\mathrm{p}<0.001$ ) and use of supportive therapy (all $\mathrm{p}<0.03$ ). Patients receiving supportive therapy more often received antibiotics than those without supportive therapy: oxygen $(17.4 \%$ vs $1.4 \%, \mathrm{p}<0.001)$, nasogastric tube feeding $(15.5 \%$ vs $5.7 \%, \mathrm{p}=0.03)$ and ventilation $(\mathrm{CPAP})(48.3 \%$ vs $5.3 \%, \mathrm{p}<0.001)$.

Conclusion The use of antibiotics is substantially lower than previously reported in any geographical region. With length of stay and use of supportive care comparable to other countries, we believe the finding supports a conservative approach in bronchiolitis management.

\section{REFERENCE}

1 Skjerven $\mathrm{HO}$, et al. Racemic adrenaline and inhalation strategies in acute bronchiolitis. N Engl J Med, 2013.368(24):p.2286-93

\section{Necrotizing Enterocolitis}

\section{PS-181 PROBIOTICS (INFLORAN ${ }^{\circledR}$ ) FOR NEC PREVENTION: INFLUENCE OF ENTERAL NUTRITION}

${ }^{1} \mathrm{M}$ Thanhaeuser, ${ }^{1} \mathrm{~A}$ Repa, ${ }^{2} \mathrm{M}$ Weber, ${ }^{3} \mathrm{D}$ Endress, ${ }^{1} \mathrm{~A}$ Kreissl, ${ }^{1} \mathrm{C}$ Binder, ${ }^{1} \mathrm{~A}$ Berger, ${ }^{1} \mathrm{~N}$ Haiden. ${ }^{1}$ Neonatology Pediatric Intensive Care Medicine and Neuropediatrics, Medical University of Vienna, Vienna, Austria; ${ }^{2}$ Radiology and Nuclear Medicine, Medical University of Vienna, Vienna, Austria; ${ }^{3}$ Pediatrics, Wilhelminen Hospital of Vienna, Vienna, Austria

\subsection{6/archdischild-2014-307384.478}

Background Probiotics may protect from necrotizing enterocolitis (NEC). Former studies in Asian populations have shown that Infloran ${ }^{\circledR}$ - a mixture of Lactobacillus acidophilus and Bifidobacterium infantis - decreases NEC by $80 \%$ in very low birth weight (VLBW) infants. Therefore, we implemented Infloran ${ }^{\circledR}$ at our department in 2010. The objectives of our study were to determine the influence of the probiotic Infloran ${ }^{\circledR}$ on NEC incidence, 